\title{
Unidad, paisaje y lugar en la fotografía colombiana, alrededor de 1900
}

\section{Unity, Landscape and Place in Colombian Photographs, around 1900}

\author{
Carlos Rojas Cocoma \\ Universidad EAN \\ carojas@universidadean.edu.co
}

\section{Resumen}

A finales del siglo xix, la fotografía de paisaje en Colombia contribuyó a crear las primeras imágenes de la región. La manera de representar el espacio, comparado con técnicas pictóricas, implicó la creación de una imagen que reconociera una unidad visual. En la presente investigación se analizaron cerca de 800 fotografías de diversos acopios documentales que permitieron interpretar cómo, mediante el desarrollo de estas imágenes y de su popularización a través de medios como la tarjeta postal, se impulsó el desarrollo de emblemas simbólicos del paisaje. Siguiendo de cerca la idea de unidad desde el pensamiento de Georg Simmel, profundizando a través de la noción de cliché de Gilles Deleuze en su seminario sobre pintura, y tomando el mismo concepto desde la obra de la lingüista Ruth Amossy, analizaremos cómo en Colombia, por medio de las adaptaciones visuales de la fotografía, el paisaje adquirió la forma visual que le permitió transformar un lugar en un ícono.

Palabras clave: Historia de la fotografía, historia Colombia, 1900, fotografía postal, Deleuze, cliché.

\section{Abstract}

Around 1900, landscape photography in Colombia contributed to create the first images of the region. Its impact on the way of representing space, compared with pictorial techniques, involved the creation of an image that recognized a visual unity. In this investigation, an analysis of nearly 800 photographs of diverse collections related to the landscape in Colombia has been carried out. Thanks to this, it has been possible to interpret how through the production of these images, and their popularization through media such as the postal card, the development of symbolic emblems of places was promoted. Following closely the idea of unity developed by Georg Simmel and deepening through the notion of cliche of Gilles Deleuze and Ruth Amossy, I will analyze how through the visual adaptations of photography landscape acquired the visual form that allowed it to transform a place into an icon in Colombia.

Keywords: History of photography, Colombian history, 1900, postcard photography, Deleuze, cliche. 
"Bref, le paysage photographique a libéré le paysage lui-même".

(Frange y Limido 19)

"And the pool answered, 'But I loved Narcissus because, as he lay on my banks and looked down at me, in the mirror of his eyes I saw ever my own beauty mirrored"'.

(Wilde, "The Disciple" 114)

\section{Introducción}

En la versión de la historia de Narciso contada por Oscar Wilde (1854-1900), el lago en el cual Narciso se sumergió por el éxtasis de admirar el reflejo de su belleza sobre el agua, llora su muerte. Sin embargo, lo que produce pena al lago no es su muerte, sino que no podría nunca más admirarse a sí mismo en el reflejo de sus ojos. ¿Pero era hermoso Narciso? Preguntaba con franca ingenuidad el lago.

Con las imágenes de paisaje ocurre un efecto similar. Acostumbrados a entender una relación pasiva de la producción de un paisaje sobre un plano, pensamos que la dinámica de estas imágenes solo compromete a la observación, dejando de lado una interacción sobre el espacio mismo. Pero la transformación de un lugar es parte del resultado de una operación de tensión y conflicto entre el espacio y las imágenes que se producen del mismo; la reproducción de la imagen legitima un punto de vista.

La operación histórica que define las formas visuales de los lugares articula todo tipo de formas técnicas, estéticas y culturales. En Colombia, alrededor del año 1900, las diferentes maneras de representar el espacio crearon una tensión estética entre lo visto y lo registrado que consolidaron la imagen del país. Esa relación de tensión y conflicto fue encontrando en la fotografía, así como en sus diversos modos de reproducción, la alternativa para ir creando paulatinamente símbolos específicos de cada lugar. Los panoramas, las calles, la fiesta o la población se transformaban en emblemas que la cámara fotográfica creaba de un lugar determinado. El presente texto busca analizar cómo a través de la fotografía y sus usos en Colombia los paisajes pasaron de un registro exploratorio a convertirse en emblemas simbólicos de un lugar a comienzos del siglo xx. Siguiendo de cerca la noción de unidad desde el pensamiento de Georg Simmel (1858-1918) en su interpretación sobre el conflicto y el concepto de cliché utilizado por el filósofo Gilles Deleuze (1925-1995) en sus seminarios sobre la pintura, así como por la lingüista Ruth Amossy (1946-) en su interpretación sobre la retórica del discurso, analizaremos cómo a través de los desplazamientos y adaptaciones visuales de la fotografía el paisaje adquirió la forma visual, casi fotogénica, que le permitió transformar un lugar en una imagen. Quizás, al igual que el giro irónico del cuento de Wilde, buscamos interpretar, en la mirada del fotógrafo, el reflejo que impacta su paisaje.

En los últimos años, diversas instituciones en Colombia han realizado poderosos esfuerzos para adquirir, preservar y divulgar los archivos fotográficos del país, lo 
que ha permitido que por vez primera se pueda acceder a amplias colecciones. Para analizar las fotografías de paisaje, se realizó la pesquisa en archivos de las siguientes instituciones: Sala de Libros Raros y Manuscritos de la Biblioteca Luis Ángel Arango y fotografías del Museo Nacional de Colombia en Bogotá, el archivo fotográfico de la Universidad Tecnológica de Bolívar en Cartagena, la Biblioteca Departamental Jorge Garcés en Cali, la Biblioteca Pública Piloto de Medellín. Adicional a ello, se consultó la colección de estereografías de la Biblioteca Pública de Nueva York y se estudió el archivo fotográfico de una expedición a Colombia digitalizado en la Biblioteca Nacional de Francia, y especialmente para el archivo europeo se ha contado con el acopio documental del Kunsthistorisches Institut en Florencia, Italia. Como archivo privado, se accedió a la colección de la Fundación Arkhé y del Proyecto Bachué, ambos en Bogotá. El trabajo de identificación se realizó tomando como parámetro fotografías de paisaje anteriores a 1910. Esto nos permitió identificar 802 fotografías que considero una muestra prudente para elaborar interpretaciones históricas sobre aspectos específicos.

\section{Antecedentes}

En el siglo xix, a la par de los relatos de viajes, la pintura de paisaje tuvo un lugar destacado en la producción cultural colombiana. Desde la tradición pictórica de las miniaturas y la expedición botánica realizada en el ocaso del reinado hispánico entre 1783 y 1816, la acuarela y la pintura se consolidó con un grupo de artistas que afianzarían a fines de siglo lo que ha sido denominado históricamente como la Escuela de la Sabana (Fajardo). Las artes plásticas se enriquecieron de los desplazamientos de artistas y viajeros - o más precisamente: artistas viajeros - que permitían que el arte colombiano siguiera de cerca los procesos artísticos que sucedían en el mundo occidental. Artistas como Dositeo Carvajal (1818-1872), que intercambió experiencias artísticas en el Perú, o Andrés Sanz de Santamaría (1860-1945), que vivió personalmente el París de la belle époque (Varios autores), se integraban al grupo de viajeros que, por azar o por decisión propia, se aventuraban a representar el paisaje de un país que resultaba idóneo para la curiosidad viajera, así como para la búsqueda romántica de la experiencia de la naturaleza. Auguste Morisot (1857-1951), Albert Berg (1825-1884) o Edwin Church (1826-1900), son ejemplos de pintores que, rastreando las experiencias de exploradores como Alexander von Humboldt (1769-1859), interpretaron la naturaleza colombiana y el paisaje en poderosas obras plásticas (García Castro; Sanz de Santamaría; Driver). Esta larga tradición contribuye a explicar por qué, cuando el Gobierno nacional emprendió una Comisión Corográfica en 1859 destinada a reconocer los límites geográficos así como los paisajes de la nación, su director rechazaría la fotografía como método exploratorio. Contrario a ello, crearía un equipo internacional de acuarelistas que recogieron en cerca de 214 escenas (Appelbaum; 
Uribe) un paisaje que, al día de hoy, a pesar de sus cualidades y destrezas técnicas, parecen motivos pintorescos antes que serios registros científicos. Aunque se supone que las acuarelas eran resultado de un contacto au plein air con el territorio, algunas de las pinturas también utilizaban elementos de otras referencias visuales, así como referentes totalmente imaginados.

A pesar del rechazo de Agustín Codazzi (1793-1859) de realizar la Comisión Corográfica con tecnología fotográfica, desde sus primeros años la imagen fotográfica fue la forma legítima de documentar visualmente y con objetividad el mundo (Daston y Galison; Latour). Para la misma época, la Mission Héliographique registró y documentó en placas fotográficas el patrimonio francés (Rouillé; Uribe), y unos años más tardes los hermanos Alinari (1852) y Giacomo Brogi (1822-1891) harían lo mismo con el patrimonio italiano. Sobre ellos, es conveniente que nos detengamos un momento.

Las fotografías de los Alinari y de Giacomo Brogi serían la documentación más rigurosa realizada sobre el patrimonio italiano, así como de algunos países cercanos. El proyecto seguía de cerca el recorrido del Grand Tour: el viaje en el cual aristócratas realizaban una experiencia cultural y de aprendizaje recorriendo de norte a sur los lugares emblemáticos del territorio italiano. A pesar de que los registros de "vistas" fue relativamente escaso en comparación con los registros de obras de arte, sus fotografías hicieron parte del mercado que popularizaría las fotografías de lugares italianos. Por ello a partir de 1890 en el catálogo que realizaron los Alinari se comenzaron a incluir vistas de ciudad, calles y escenas de la vida cotidiana de ciudades como Nápoles o Roma. Tal como lo menciona Filippo Zevi, en Italia, gracias a esas fotografías y a su exitosa difusión a través de medios como la tarjeta postal o reproducciones de formato medio, "una foto tras otra, se construyó una imagen de Italia que resultará familiar a los italianos, hasta convertirse por un largo periodo en la única imagen conocida" (Zevi 254).

Pero a pesar de tratarse hoy de fotografías icónicas del 1900 italiano, estas se soportaban sobre puntos de vista y formas de representación que venían de la tradición misma del Grand Tour a partir del siglo xvinI e incluso antes; por lo tanto, las "formas de ver" tenían un soporte previo que facilitaba la intención a la hora de realizar el encuadre fotográfico. El lugar visual por excelencia donde el Grand Tour posó la imagen fue en la implementación de las vedute. La imagen pictórica de las vistas de ciudad, por ejemplo, que heredaba de la tradición paisajística una "forma" de ver en la cual el punto de fuga se proyectaba sobre un horizonte desde un punto elevado. Esto lo podemos ver en casos como la Plaza de San Carlos, en Turín, en la cual la representación simétrica de la plaza y su proyección hacia el centro realizada en un grabado en la primera mitad del siglo XviII no dista de la representación realizada con la cámara fotográfica por Edizioni Brogi, hacia 1890. Aunque la estatua que representa a Emanuele Filiberto, y que fue erigida en 1864, interrumpe la composición, no lo hace ni con la perspectiva ni con la intención de uno y otro, que se mantienen casi idénticos entre el grabado y la imagen fotográfica [Figuras 1 y 2]. 


\section{FIGURA 1}

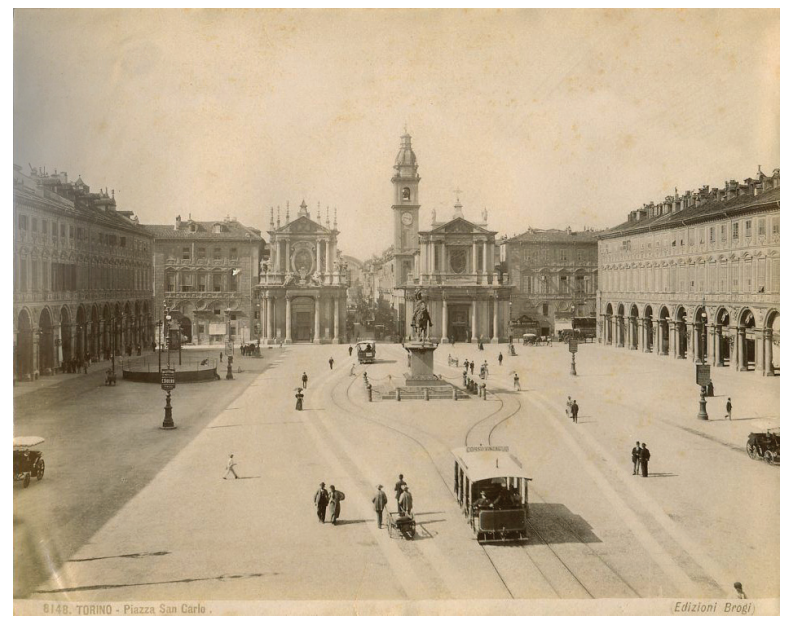

Piazza San Carlo. Giacomo Brogi.

Kunsthistorisches Institut, Florencia, 1898.

\section{FIGURA 2}

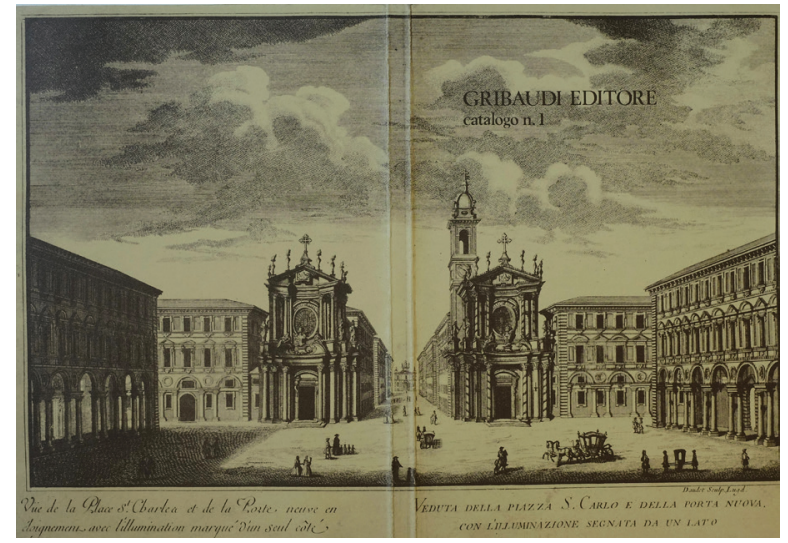

Veduta della Piazza S. Carlo. Gribaudi. Grabado.

Kunsthistorisches Institut, Florencia, siglo XviII.

Es complejo sintetizar la diversidad y cantidad de publicaciones de viajeros que hicieron su recorrido hacia Sudamérica desde mediados del siglo xx, pero sin duda todos representaron a su modo una especie de Grand Tour expandido. Los numerosos viajeros que escribieron o pintaron su recorrido traían consigo además un punto de vista particular y romántico en que la experiencia, sea por semejanza o por extrañeza, miraba constantemente hacia el paisaje europeo. Incluso los viajeros locales utilizaban como recurso retórico ese sentido de familiaridad y extrañeza que, alternativamente, se incorporaría al lenguaje nacionalista y positivista sobre la modernidad y el progreso. 
Pero mientras en Europa la vedute pintada precedió cronológica y estéticamente a la vista fotográfica, en Colombia las dos tuvieron que vérselas en simultánea con un mismo espacio, creando una tensión estética evidente.

En la segunda mitad del siglo XIX, la discusión entre el arte pictórico y el arte fotográfico se mantuvo con bastante frecuencia en los círculos artísticos colombianos. La particularidad era que, además de su aprobación en el campo artístico, en muchas ocasiones los artistas eran igualmente fotógrafos, así que alternaban asiduamente sus dos actividades. Si bien en 1899 se comienza a marginar la fotografía de los salones artísticos nacionales — volvería solamente hasta 1973 (Calderón Schrader)—, la fotografía sirvió de base para que la pintura adquiriera un nuevo aire en temas como el retrato, y hasta cierto punto el paisaje. Los pintores usaban reiteradamente la fotografía para sus composiciones y la veían como un recurso aliado, no un contendor. De acuerdo a Eduardo Serrano (1939-), los artistas José María Espinosa (1796-1883), Ramón Torres Méndez (1809-1885), Victorino García (1791-1870), Celestino Martínez (1820-1885), Manuel Dositeo Carvajal (1818-1872), Eugenio Montoya (1860-1923), Ricardo Moros Urbina (1865-1942), Pantaleón Mendoza (1855-1910) y Ricardo Acevedo Bernal (1867-1930), entre otros, "no ocultaban, sino que comentaban libremente, e inclusive anunciaban en la prensa, el apoyo de sus lienzos en el retrato fotográfico” (Serrano 213).

\section{Paisaje}

Como género, el retrato contribuyó al desarrollo de estudios fotográficos en las principales ciudades del país. Pero mientras este tuvo una gran demanda comercial, la fotografía de paisaje estuvo relegada a una producción mucho más discreta. El daguerrotipo y posteriormente la difusión de las cartas de visita lideraron el mercado fotográfico en Colombia. Aunque la fotografía fuera más económica que el retrato pintado, constituía en todo caso un lujo que solo una élite limitada podía costearse. Por otra parte, aunque la revolución de Kodak impactó y popularizó la fotografía, los estudios mantuvieron su actividad y se convirtieron incluso en emblemas de la ciudad que mantendrían vigente la tradición de "hacerse un retrato". El paisaje, por el contrario, a falta de un público directo que costeara la iniciativa, tenía que encontrar maneras diversas de difusión (Ávila). No obstante, esta falta de clientela fue la oportunidad de una posibilidad creativa, pues si bien la cultura visual del paisaje pintado circulaba en las clases altas, el paisaje fotográfico encontraría su nicho ideal en la difusión popular.

Como un paso intermedio entre pintura y fotografía, la aparición del fotograbado fue un recurso que consolidó la difusión del paisaje y permitió que se difundiera a una comunidad y por vez primera las imágenes del país. En el ámbito nacional, el caso más conocido fue la creación del Papel Periódico Ilustrado, un medio que entre 1881 y 1888 produjo 604 grabados en 104 ediciones (Jiménez Hernández, 2012), y fue igualmente un espacio de interacción entre artistas, fotógrafos y grabadores de la época 
que giraban alrededor de la figura de Alberto Urdaneta (1845-1887) y la Escuela de Bellas Artes (Pérez Benavides). Con una prosa de carácter romántico, los fotograbados dedicados al paisaje, el 39\% del total de imágenes fueron referentes de calles, edificios y accidentes naturales que buscaban ser promovidos como un gran proyecto nacional. Seguramente, la lectura y difusión pública de este medio fue parte de la prehistoria del espacio cultural y político que vendría a hacer el espacio del café en Colombia (König).

El perfil de los numerosos viajeros que publicaron textos sobre Colombia era tan diverso como generoso, desde coleccionistas de orquídeas a cazadores de cocodrilos, de naturalistas a diplomáticos ociosos, de ingenieros militares a poetas. Aunque muchos incluían bocetos realizados por ellos mismos o adaptados de alguna imagen, algunos trabajos buscaban con rigurosidad adaptar el trabajo fotográfico al texto impreso a través de fotograbados, como lo fueron el trabajo del suizo Ernst Röthlisberger (18581926) o el del francés Henri Candelier (1890-1893) (Candelier; Röthlisberger). Esta interacción entre artistas que realizaban retratos desde la fotografía, y fotografías que se adaptaban a través de un proceso técnico hacia el grabado, llevaron a una tensión estética en la creación simbólica del paisaje colombiano. El primer escenario plástico en el cual se encuentran las diferencias lo constituyó la identificación del punto de fuga en la perspectiva. Previo a la fotografía en Italia, las imágenes pintadas y grabadas del Grand Tour y su difusión no eran solo registros de un lugar, también constituyeron la lección decisiva sobre las formas de posar la mirada sobre un paisaje.

La tradición de las vedute, y seguramente el uso de artilugios como la cámara oscura para su desarrollo, consolidaron una interpretación sólida sobre la perspectiva y el punto de fuga en el paisaje abierto. Por ello se encuentran álbumes fotográficos que desde 1870 reconstruyeron en fotografía el recorrido romántico del Grand Tour. En Colombia el abismo entre el paisaje pintado y su reproducción fotográfica producía tensiones más pronunciadas. Podemos verlo en el caso del género de las "vistas". En la mayoría de acuarelas de la región realizadas a mediados del siglo xix, se posaba el mismo horizonte plano sobre las imágenes que planteaban tres planos estructurados: un plano panorámico donde difuminado en la atmósfera se esbozaban sutilmente los elementos del paisaje. En el intermedio, el paisaje era definido a través de aspectos particulares, y por último, un primer plano donde se acompañaba la escena con situaciones y personajes de los cuadros de costumbres. Tal es el caso de las vistas que se produjeron sobre la ciudad de Cartagena y Santa Marta, realizadas por Edward Mark (1817-1885) en 1843 [Figuras 3 y 4]. En la primera, el puente permite establecer esa conexión entre planos, mientras que en la segunda la forma singular de la montaña del fondo, que culmina con el convento en el cerro de la Popa, define la profundidad de la composición.

En las que corresponden a Santa Marta, Edward Mark decidió implementar parte de las ramas de los cactus que, efectivamente, corresponden a la vegetación árida de la región. No obstante, es en los planos medios donde determina aquello que resulta singular: los barcos o la vista de la ciudad [Figuras 5 y 6 ]. 


\section{FIGURA 3}

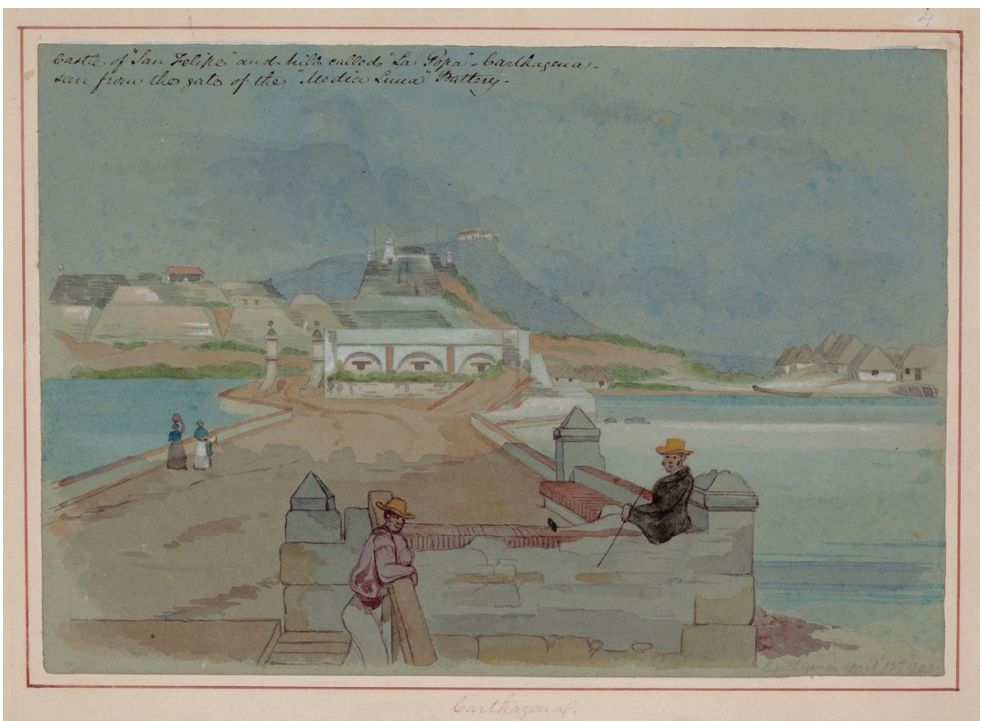

Vista de Cartagena. Edward Mark. Colección de Arte, Acuarela, Colección de arte, Banco de la República, Bogotá, 1843.

\section{FIGURA 4}

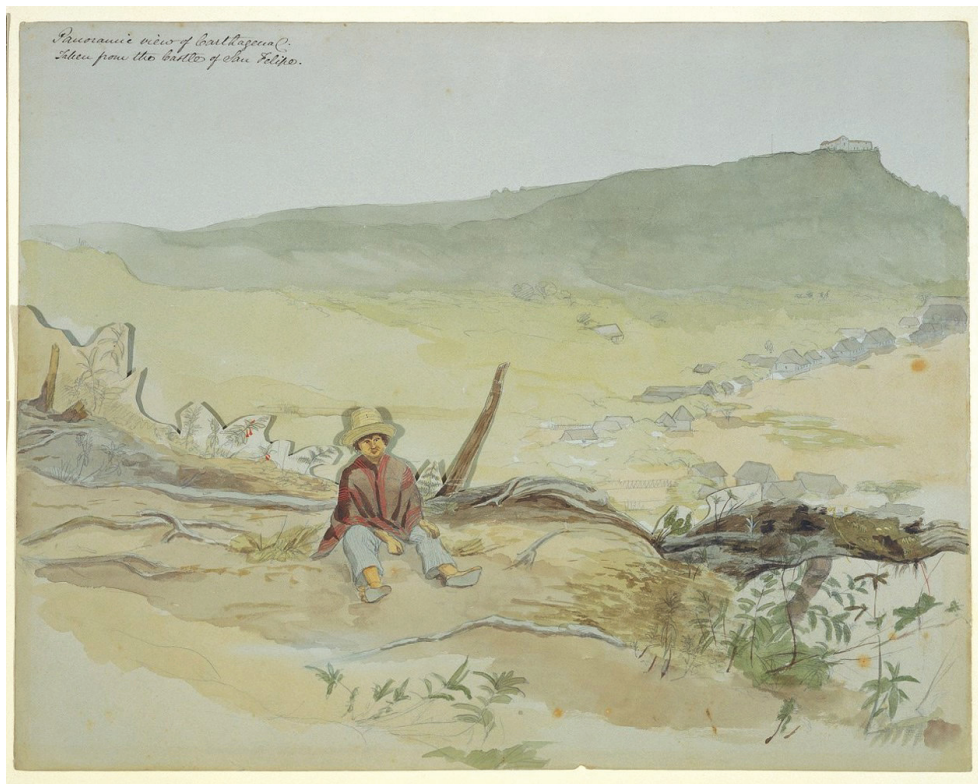

Vista de Cartagena. Edward Mark. Colección de Arte, Acuarela, Colección de arte, Banco de la República, Bogotá, 1843. 


\section{FIGURA 5}

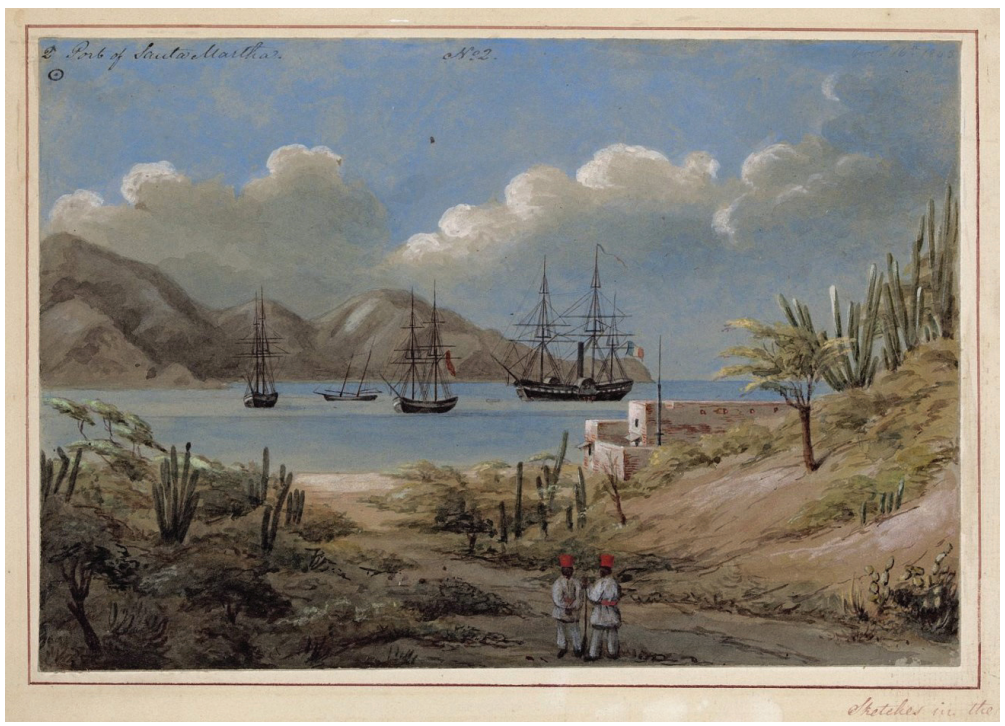

Vista de Santa Marta. Edward Mark. Colección de Arte, Acuarela, Colección de arte, Banco de la República, Bogotá, 1843.

\section{FIGURA 6}

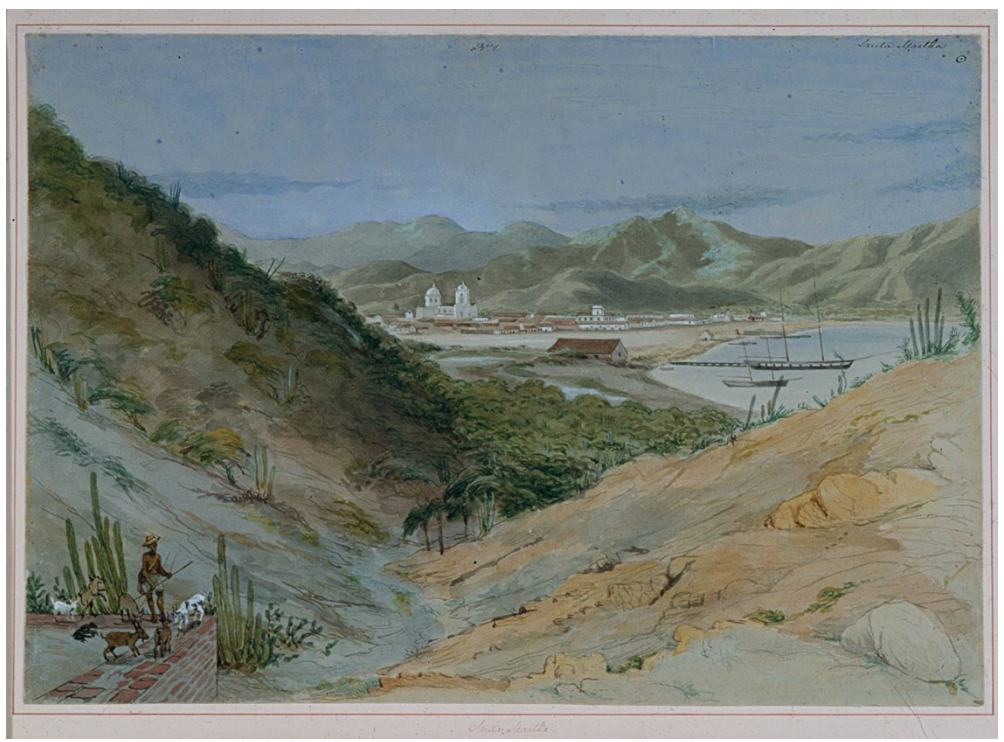

Vista de Santa Marta. Edward Mark. Colección de Arte, Acuarela, Colección de arte, Banco de la República, Bogotá, 1843. 
Comparemos la forma de representación de los mismos lugares a través de la fotografía. La primera fotografía publicada e identificada es la correspondiente a la "vista general de la Bahía", cuya fecha de envío es el 2 de agosto de 1908 [Figura 7]. La fotografía choca con todo lo que corresponde a una composición de vista: no tenemos la escala humana que dimensione la escena; ni la vegetación árida ni los pobladores acompañan esta escena que además luce vacía, abandonada. El plano medio de la situación, clave en las otras escenas de vistas, está acá perdido del todo. La fotografía está retocada, lo que es evidente en la forma delineada de las casas, y en la sutil creación de un cielo nublado, totalmente imposible para la emulsión de la época. Los barcos se proyectan en el horizonte como líneas perdidas, lejos de parecer los grandes galeones de las vistas pintadas de la ciudad. Pero el aspecto más evidente, y que es además una condición básica en la composición de un panorama, es que el horizonte que debe estar siempre debidamente alineado, acá se encuentra inclinado a lado y lado de la imagen, ligeramente desviado hacia el costado izquierdo.

\section{FIGURA 7}

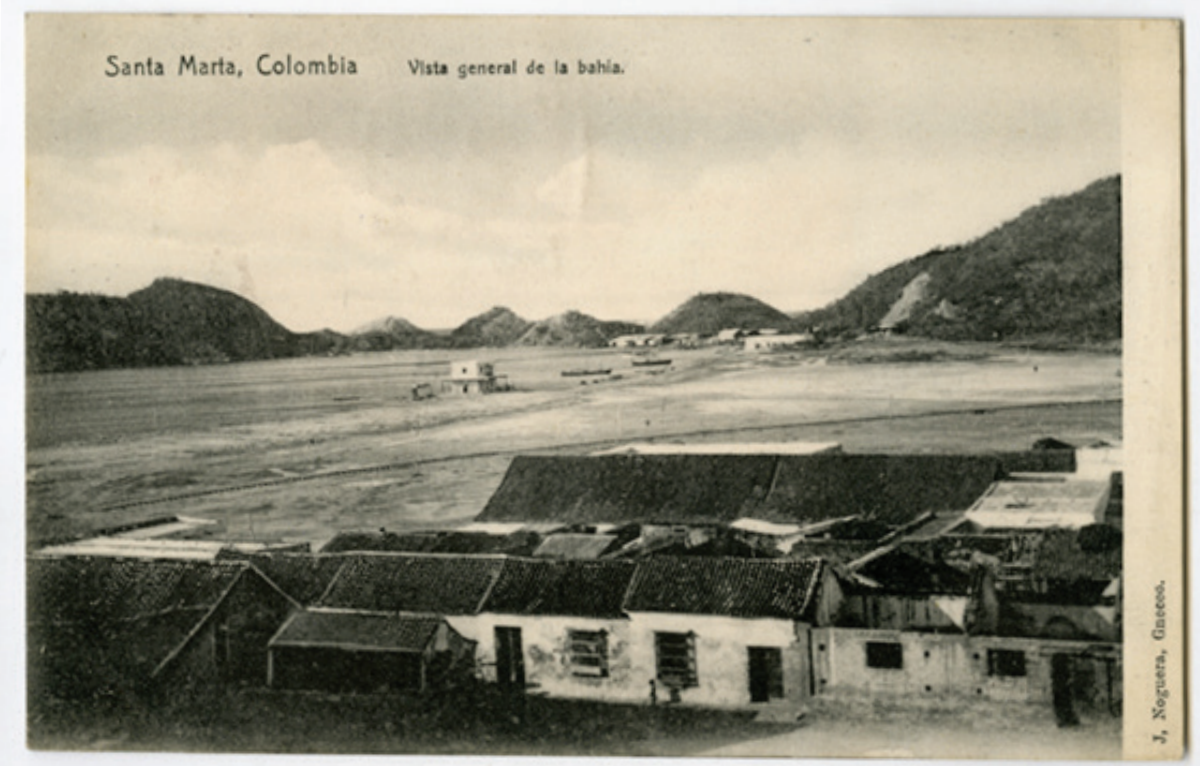

Santa Marta. Vista general de la bahía. J. Gnecco. Cartulina postal, blanco y negro. Sala de Libros Raros y Manuscritos, Biblioteca Luis Ángel Arango, Bogotá, 1908. 
Además de la inclinación, la deformación del plano se justifica porque se trata de un lente con mayor ángulo de visión (lo que hoy conocemos como gran angular) que al inclinarse sobre un plano amplio distorsiona el horizonte. En términos estéticos la dificultad es relevante, pues implicó establecer una forma diferente de composición - la veduta - que dependía de la línea del horizonte para ser definido, como se puede ver en la gran mayoría de láminas de la Comisión Corográfica. A diferencia de la pintura, el lente fotográfico decide sobre el ojo el lugar del punto de fuga y connota su evidencia. El fotógrafo puede decidir dónde se proyecta el punto de fuga, pero es el único elemento que no se puede transformar en la captura de una foto. En estas composiciones de paisajes y vistas, la presencia fuerte del punto de fuga recuerda las primeras pinturas renacentistas que proyectaban su evidencia sobre el plano. Quizás es debido a ello que las composiciones más logradas para las postales de las primeras décadas, en lugar de grandes panoramas, sean discretas proyecciones de calles y senderos donde el punto de fuga, en lugar de esconderlo o disimularlo, se proyecta. La palabra "objetivo", con su doble definición en español de "lente" así como de "fijación" no puede ser más clara: se determina por un punto sobre el plano sobre el cual se proyecta una profundidad. Curiosamente, buena parte de los debates y analogías con los que se reflexionaba sobre la fotografía versaban alrededor de la química y la impresión, pero muy pocos al respecto de la física de la óptica; ello a pesar de que, para 1900, París ya tenía 3.000 personas viviendo de la fotografía y decenas de talleres dedicadas al negocio de los lentes fotográficos (D’Agostini).

\section{Unidad}

Si hay un aspecto particular que surge en la composición aparentemente descuidada de la tarjeta postal es la ausencia de decoración romántica. Ni la grandeza de un paisaje, ni la singularidad del espacio, ni el carácter local de la arquitectura o la naturaleza son puestos en evidencia. De repente la fotografía fue capaz de despojar de todo tipo de encanto el escenario dispuesto. Ya que la imagen panorámica es casi incapaz de decidir sobre la disposición de los elementos, se ve liberada, aunque a su vez desnuda, de los elementos compositivos que construyen una narración visual del espacio. Esa gracia perdida, que será el primer paso para que la fotografía se redescubra en su propia naturaleza plástica, no fue en todo caso una pérdida sin lucha. En la estereografía fechada en 1910, vemos una forma de aquella fricción [Figura 8].

En términos de detalle y calidad de la imagen, la fotografía de la vista de Santa Marta está mucho mejor lograda que la postal de la United Fruit Company. Podemos ver que retoma los elementos clásicos que veíamos en las vistas de la comisión corográfica: en el fondo un paisaje montañoso que difumina un horizonte esta vez bien nivelado, un plano medio que toma la ciudad y la convierte en el centro del paisaje y un primer plano con un viajero que observa hacia el horizonte, como una 


\section{FIGURA 8}

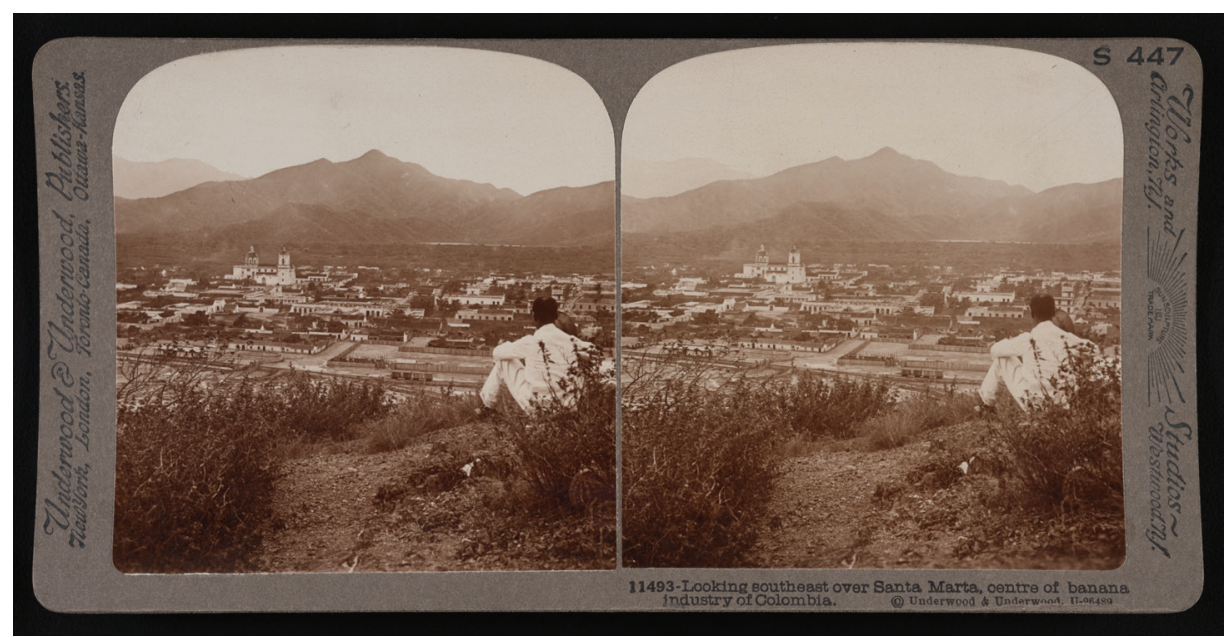

Looking to Southeast over Santa Marta, Centre of Banana Industry of Colombia. Underwood y Underwood. Estereografía. The New York Public Library. Nueva York / Londres / Toronto. Ca. 1910

escena de Caspar David Friedrich (1774-1840). Incluso la vegetación seca vuelve a incluirse como parte de la decoración. Aunque el mercado de la estereografía disminuyó ostensiblemente con la aparición de la postal fotográfica, su producción con fines recreativos se mantuvo en el mundo incluso hasta la década de 1940 (Lorenz) y era todo un referente estético de la fotografía. El retorno necesario de los tres planos sobre la imagen obedece al juego escalado de la tercera dimensión, pues era gracias a esa figura en primer plano que la ilusión óptica de la profundidad resultaba más efectiva. La escena, sin embargo, no deja de parecer artificial. La composición establece la armonía de los tres planos organizada adecuadamente, quizás no para satisfacer la ilusión óptica de profundidad tanto como para obedecer a cánones plásticos establecidos. Incluso la figura al costado derecho de la escena encuadra en la imagen de tal forma que pierde toda espontaneidad. La fotografía está cargada de una naturalidad que resulta pastiche, una imitación de un gesto espontáneo que pone en evidencia el truco romántico, tan efectivo en la pintura. Pero es esa "falsa naturalidad", esa pose demasiado forzada de "espontaneidad" la que ofrece al paisaje el primer intento de unidad.

El concepto de unidad fue desarrollado por Georg Simmel (1858-1918) para diferentes objetos de interés — incluido el paisaje-, y que podemos considerar para comprender las tensiones históricas que se dieron en las diversas representaciones del paisaje colombiano. En una primera fase de la obra de Simmel, en su 
ensayo sobre los paisajes de Böcklin (1895), el sociólogo interpretó el carácter del Stimmung (palabra intraducible del alemán) como lo que permite la armonía de la oscilación entre una totalidad de elementos dispersos llamada naturaleza, ante el marco que delimita y crea un paisaje que responde a la emotividad del artista. El autor se apoyó en una idea de un paisaje como un gesto visual que busca demarcar ese "todo" sobre un plano subjetivo (Wegelin). Recoger en una imagen un paisaje debía ser: "una sucesión de manifestaciones naturales extendida sobre la corteza terrestre compendiada en un tipo peculiar de unidad" (Simmel, El individuo y la libertad 180). No obstante, si bien su teoría estética permite comprender parte de la relación entre el artista y el paisaje - una relación que no es simple ni responde a una dinámica de "causa y efecto"-, ofrecía un panorama romántico que aún recuerda la experiencia de la naturaleza como un punto de quiebre para interpretar el paisaje. Cuando Simmel hablaba de unidad en el paisaje no estaba alejado de su propia interpretación de la obra de Arnold Böcklin (1827-1901) y su carácter simbólico. Su visión se queda corta ante otras visiones sobre el paisaje, incluso contemporáneas a su tiempo, como la noción de "Paisaje Cultural” de Carl Sauer (1889-1975) (Sauer), según la cual el paisaje es transformación social, u otras nociones contemporáneas como la de Yi-Fu Tuan (1930-), quien planteaba la evidencia de la interpretación temporal en el paisaje (Tuan). Pero la idea de unidad es aún relevante y vale la pena reivindicar su vigencia. En un texto posterior dedicado al conflicto y publicado en 1904 (“The Sociology of Conflict", publicado en 1904 [Simmel, El individuo y la libertad 44]), Simmel retoma la noción de unidad, pero esta vez para interpretar un proceso social. En su texto, Simmel analiza la capacidad e importancia del conflicto para que sea posible la composición real de una unidad. Dice el autor: "los movimientos convergentes de la unidad social están inseparablemente entrelazados con los divergentes. Un grupo exclusivamente centrípeto y armónico, una pura y sencilla 'reunión', no sólo no existe en los hechos, sino que no encarnaría ningún auténtico proceso vital" (Simmel, Sociología 300). Es esa vitalidad la que el autor defiende detrás de una "sociología positiva del conflicto" según la cual "lo negativo, el dualismo, representa un papel absolutamente positivo, allende los destrozos que haya podido ocasionar en la esfera de las relaciones individuales" (Simmel, Sociología 302). En conclusión, la unidad solo constituye una vitalidad cuando proviene del ejercicio dinámico, de la fricción, que produce el conflicto. Ahora ¿Cómo podemos traer esos elementos al análisis del paisaje fotográfico?

Hemos relacionado un primer elemento en conflicto inherente a la fotografía de vistas en Colombia: la relación entre horizonte y punto de fuga. La tensión propia del paisaje fotográfico tenía que vérselas con la manera según la cual el horizonte perfecto y plano de la pintura no podía acontecer en el objetivo específico y concéntrico del punto de fuga fotográfico. Así que la fotografía debía pasar al centro de la escena el punto de fuga en lugar de intentar dejarlo discretamente oculto. Para ver en un primer momento el plano estético de la fotografía, el punto de fuga debía dejar de ser visto 
como un artilugio de la ilusión de profundidad sobre el plano para pasar a ser el centro protagónico de la imagen fotográfica. Lo podemos ver en dos momentos fotográficos sobre un mismo elemento representado. La Casa Flohr, Price \& Company reprodujo dos escenas sobre el muelle de Puerto Colombia. En la primera, la relación entre el horizonte y el punto de fuga es evidente [Figura 9]. La foto mantiene la línea del horizonte, el puerto se proyecta hacia su propio punto mientras que la escena del primer plano resulta completamente irrelevante. Es tan diciente la poca importancia que tiene el primer plano, que en la edición la fotografía ocupa casi el $50 \%$ de la postal, mucho menos de lo que se hacía habitualmente en el mismo formato de la casa editorial.

En la segunda imagen podemos ver un ángulo diferente [Figura 10]. En el primer plano, cuatro hombres posan. Todos tienen prendas similares, lo que no es común en la época. Uno de ellos posa con un bastón. Probablemente uno de ellos sería el propio Otto Flohr, fundador de la casa que produjo las postales y propietario de tierras cercanas al puerto. Pero el centro de atención lo constituye la larga perspectiva y dimensión que produce la obra arquitectónica a sus espaldas.

El muelle fue inaugurado en 1888 y para el momento era casi un emblema nacional, pues constituía uno de los más grandes del mundo. La importancia económica debía ir a la par de su importancia simbólica, pues aunque se encontrara a 15 kilómetros de la ciudad de Barranquilla, debía ser asociado a la que era entonces la ciudad más moderna de Colombia. Su importancia y su carácter debían tener una forma singular desde la cual el punto de fuga dejaba de ser la "condena" estilística para pasar a ser el punto de partida. En este caso, se logra relacionando el punto de fuga de la proyección fotográfica con el protagonista central de la escena: el puerto. La unidad de la imagen se encontraba ubicando en un mismo lugar el objetivo de la imagen (el tema) con el dispositivo del punto de fuga, integrarlo a la composición, encontrar en él un aliado y no un contendor a disfrazar, encontrar la unidad de su propia estética.

Si el punto de fuga dejó de ser un efecto óptico o la parte "incómoda" de la composición, fue necesario encontrar el tipo de composición que funcionara para esta. De 802 fotografías de paisaje identificadas en Colombia, 132 responden a la categoría de calle. Todas tienen en común la proyección del punto de fuga en el momento en que la calle se confunde con el horizonte. La imagen de Pasto no puede ser más clara [Figura 11]; en ella, los transeúntes posan en cada costado de los muy estrechos andenes, mirando a la fotografía pero sin ocupar el centro de ella. Aunque no pase por la vía ningún transporte, el centro se deja vacío, manteniendo limpia la proyección que conduce al final de la perspectiva. Esta escena no era dependiente de la geografía o forma de la ciudad, pues como esta imagen podemos ver escenas como la fotografía de la calle Universidad o la calle de Manga, producida por la casa C. F. R. S. en Cartagena, como la Calle del Comercio, en Tumaco, o la Calle Real de Barranquilla, realizada por la Flohr, Price \& Company. Incluso, a pesar de 


\section{FIGURA 9}

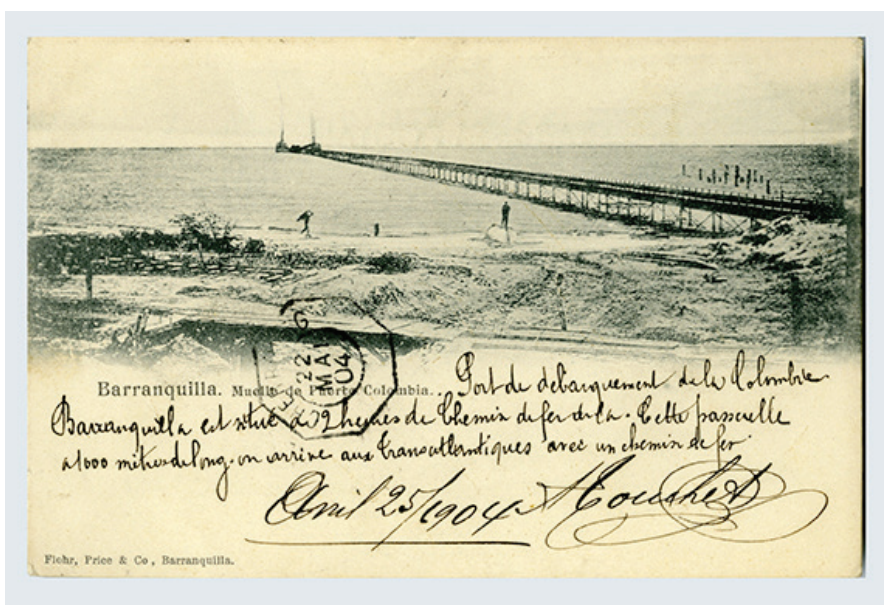

Muelle de Puerto Colombia. Flohr, Price \& Co. Cartulina Postal a blanco y negro. Sala de Libros Raros y Manuscritos, Biblioteca Luis Ángel Arango, Bogotá, 1904.

\section{FIGURA 10}

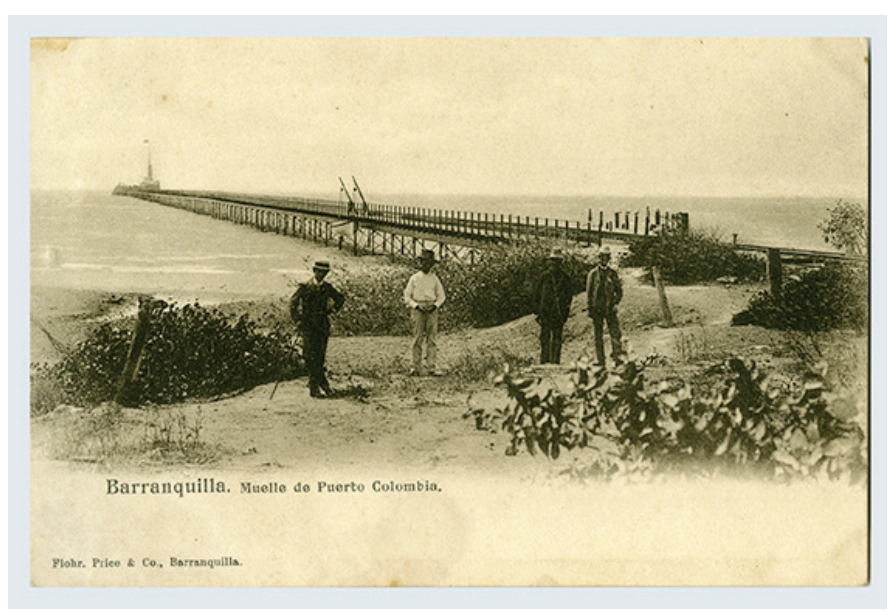

Muelle de Puerto Colombia. Flohr, Price \& Co. Cartulina Postal a blanco y negro. Sala de Libros Raros y Manuscritos, Biblioteca Luis Ángel Arango, Bogotá, 1904. 
FIGURA 11

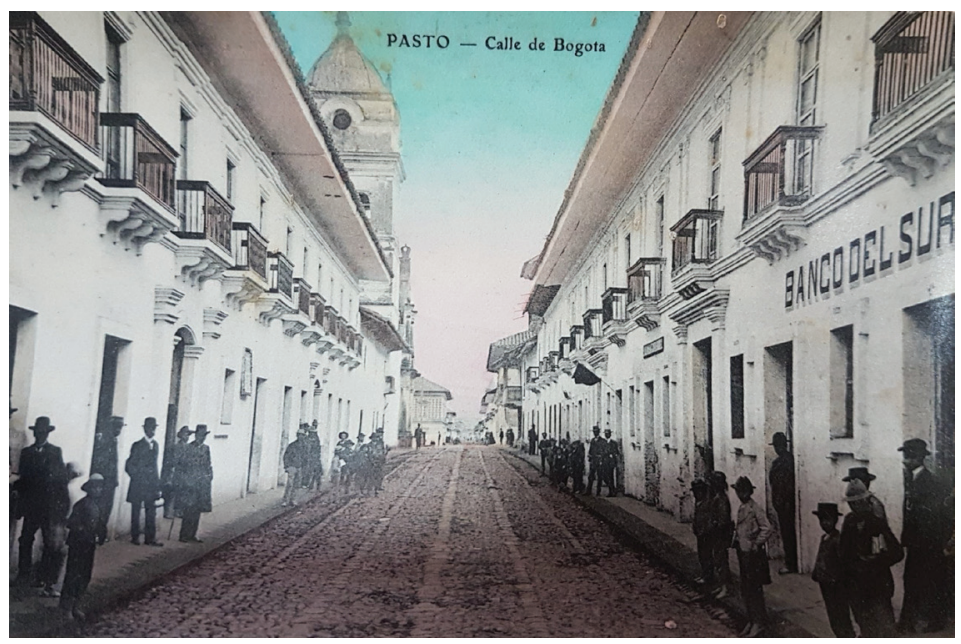

Pasto/Calle de Bogotá. Anónimo. Cartulina postal blanco y negro coloreada. Colección Privada, Proyecto Arkhé. Bogotá. Ca. 1906.

\section{FIGURA 12}

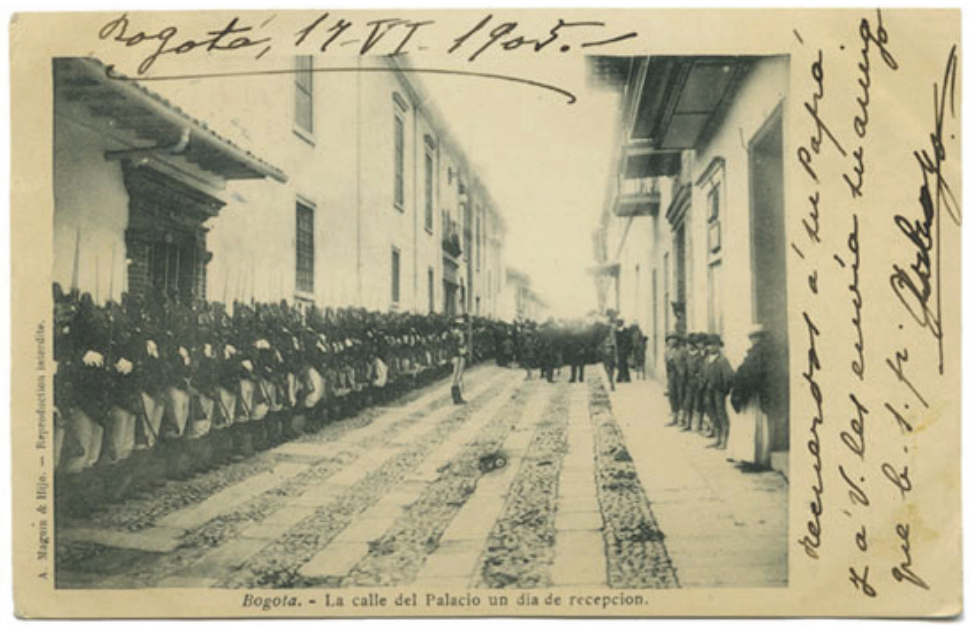

Bogotá-La calle del Palacio un día de Recepción. Magris e

hijos. Cartulina Postal a blanco y negro. Sala de Libros Raros y Manuscritos, Biblioteca Luis Ángel Arango, Bogotá, 1905. 
que la escena correspondiera a un motivo particular, como una celebración o un desfile de armas, era inevitable que la profundidad no adquiriera el lugar central en la temática presentada, como en el caso del desfile ofrecido en Bogotá para la postal de 1905 [Figura 12].

\section{Cliché}

Dejando de lado el asunto de la perspectiva, el segundo elemento que conduce al estudio de la unidad en el paisaje fotográfico en Colombia es resultado de un proceso social que responde a la importancia de la copia como condición creativa y activa en la consolidación de la imagen, y no solo como su reproducción. Como se ha podido concluir, hay ciertos patrones comunes en las imágenes analizadas. El fotógrafo mira hacia el mismo ángulo, produce una y otra vez la misma imagen. Incluso en el caso de las postales, la misma fotografía se copia reiteradamente modificando su uso y su formato. Esto no es solo un caso colombiano, las imágenes se repiten, se parecen, se imitan unas a otras hasta que van adquiriendo una misma forma, al mismo tiempo tan familiar como extraña. A cualquier observador ajeno al estudio de la fotografía las imágenes le pueden parecer todas iguales, y eso va más allá del uso obligado del blanco y negro. ¿Por qué la imitación? ¿Por qué la cantidad de imágenes similares de calles, de casas, de vistas? ¿Por qué el auge de la reproducción fotográfica? A pesar de que proyectos como el del Papel Periódico Ilustrado tenían como propósito el reconocimiento social y público de los paisajes y lugares colombianos, no fue en empresas con proyectos nacionalistas o movimientos altruistas donde se comenzó a establecer la visualidad de los lugares sino en escenarios más mundanos y populares, a los que vale la pena analizar.

A finales del siglo XIX, la fotografía de paisaje encontró a través de la tarjeta postal un medio desde el cual transformó la comprensión y reconocimiento del espacio público. Desafortunadamente, la historia de la fotografía centra la atención más sobre los fotógrafos que elevaron a una categoría artística la técnica fotográfica, dejando al costado el estudio de la reproducción de la imagen o los usos por parte de la cultura popular, lo que es una ironía histórica, teniendo en cuenta que los momentos decisivos de la historia de la fotografía los constituyeron la manera en que poco a poco pasó de ser una pericia y consumo de unos pocos a un medio accesible para la gran mayoría. En ese sentido, el fenómeno de la tarjeta popular puede ser considerado la primera dinámica visual e industrial de la cultura popular, y como antesala del cine, la radio, la televisión o las revistas impresas, fue la plataforma para transformar las relaciones con la comunicación epistolar no solo en aras de su economía, sino también en la producción de un escenario cotidiano y familiar. Lo que comenzó en 1866 en Austria como una solución legal y administrativa, para principios del siglo xx era una revolución mediática. Las cifras globales permiten dar cuenta de su escala: En Alemania, en el 
verano de 1900, el servicio de Correos dio curso a más de veinte millones de postales, de las cuales el $45 \%$ pertenecían a turistas. Solo de Berlín salieron diariamente más de 130.000 postales (López Hurtado). En Francia, de 8 millones de postales enviadas en 1899, el número de tarjetas postales aumentó a 52 millones en 1900, y entre 1905 y 1906 ya se habían producido 600 millones de postales (Chéroux y Eskilden 196). En 1902, la fototipia de los suizos Hauser y Menet, la primera editora de postales de España, aseguraba producir mensualmente medio millón de tarjetas. Entre junio de 1907 y junio de 1908 fueron enviadas más de 667 millones de tarjetas postales desde Estados Unidos, la mayoría de ellas con fotografías (Warner Marien 170).

Del mercado global de la tarjeta postal en la primera década del siglo xx, el noventa por ciento era dedicado a la fotografía. Es por ello que para analizar la riqueza de la tarjeta postal hay que interpretarla como imagen, como medio de comunicación y como escenario de intercambio de una cultura visual. Legitimar su lugar no implica necesariamente reivindicarla en escenas plásticas o artísticas que quizás no se merece. La postal depende de su propia mundanidad: es estereotipada, trivial, superficial, económica y no responde, a diferencia de otro tipo de coleccionismo, a un patrimonio de valor exclusivo. Pero es justamente allí donde radica su valor cultural, pues desarrolla al mismo tiempo los emblemas de los lugares, así como formas específicas de relacionarse con ellos. Se trata de imágenes que a fuerza de repetirse, de transformarse en clichés, componen una interpretación nueva del lugar, despojada de su propia artificialidad.

De acuerdo al diccionario Larousse, la palabra cliché fue una apropiación directa de la jerga técnica de la fotografía. Aunque se conocía así al molde que se utiliza para la impresión sobre papel, el término se hizo popular para referir al negativo en el momento en que reproduce copias positivas en papel impreso, en la década de 1860 (Amossy y Lyons 34). Si bien no nace con la fotografía el uso retórico de los "lugares comunes", el hecho de que la palabra cliché surja en un contexto de la "cultura de la copia” (Schwartz) puede resultar más que una coincidencia. En los estudios del lenguaje, el estudio del uso del cliché ha puesto en evidencia un desprestigio similar al que tiene el estudio de la tarjeta postal (Franco y Olmos), y sin embargo es parte esencial y constante de las formas familiares del discurso. El cliché hace referencia a la repetición de una descripción conocida hacia algo, a una expresión que produce una imagen reiterativa ya conocida y por lo tanto adquiere una forma casi banal. En la escritura, el cliché retorna a lugares popularmente conocidos en el lenguaje de forma cultural y por eso la reproducción de una expresión resulta familiar. Los ojos "azules como el cielo" o ser "libre como el viento" son formas retóricas que se afirman en el cliché. Pero antes de juzgarlo por su ausencia de originalidad, el cliché tiene un impacto decisivo en la forma en que una cultura se integra simbólicamente tal como lo ha sugerido Ruth Amossy (1946-) ("La Notion de Stéréotype" 42). Dice la lingüista: "El empleo de un efecto estilístico dirigido hacia el lugar común no conduce sólo a compartir una lengua: permite reconocerse y comunicar a través de un estilo" (41). Para analizar las formas culturales del cliché, la autora se centra en la forma en la que opera como un 
instrumento de familiaridad, particularmente en la lectura. El potencial del cliché en el lenguaje está en facilitar el flujo del texto, pues hace fluir a la lectura, contribuye a crear las representaciones visuales, favorece la identificación y da verosimilitud al argumento, todo "gracias al fenómeno de la repetición" (Amossy y Lyons 35). Estas relaciones que Amossy plantea en la escritura bien pueden adaptarse a las formas no textuales del cliché, como son por ejemplo las del cine. No es en un único uso, o una forma de comenzar (como decir "había una vez") donde el cliché se transforma en un poderoso instrumento de "familiaridad", sino en la repetición constante de su uso. "Un cliché no dispone su función fáctica aisladamente: es la multiplicidad de clichés dispuestos a lo largo de un texto que contribuyen a crear y mantener la impresión de convivencia, de ver la comunión en un mismo lenguaje" (Amossy, "D’une Culture à l'autre" 15).

El cliché maneja una forma ambigua, pues a la vez que conduce a la familiaridad de un texto, e incluso marca la "especificidad genérica de una obra literaria" (Amossy y Herschberg Pierrot 61) es considerado igualmente el gran enemigo de la escritura, como lo es también de las artes visuales. Esta dualidad demanda por parte del lector o del observador una lectura de familiaridad así como de evaluación: "En términos de esta doble recepción, el cliché se revela en sí mismo como un completo efecto de la lectura" (Amossy y Lyons 36). Pero también es un objeto de reflexión por parte de la creación. En sus estudios sobre el cine, así como en su análisis sobre la pintura, Gilles Deleuze encontraba en el cliché la fuerza creadora de la repetición. Decía el filósofo:

Si al pintor le cuesta trabajo comenzar, es justamente porque su tela está llena. ¿Llena de qué? De lo peor. Comprenden, si no pintar no sería un trabajo. Está llena de lo peor. El problema va a ser realmente el de quitar esas cosas. Esas cosas invisibles, sin embargo, que ya han tomado la tela. Es decir, el mal está ahí. [...] La tela está llena de clichés (55).

Por ello el cliché termina siendo para el arte como una especie de enemigo íntimo el cual se aborrece, pero al mismo tiempo se está determinado a convivir con él constantemente. Solo a través de su puesta en evidencia se puede escapar de él mismo, y la única manera posible de desentramarlo y de producir una fuga es a través de la repetición. Al respecto menciona Žižek: "Lejos de oponerse a la aparición de lo nuevo, la propia paradoja deleuziana es que algo verdaderamente nuevo sólo puede aparecer en la repetición" (29).

Ante la cultura de masas, la reflexión del cliché no gira alrededor de la creación de un artista. Oscila sobre la cultura misma. Si bien apenas refiere un pequeño comentario, para Deleuze la reflexión del cliché se observa también en la identidad de la imagen. Al respecto mencionó en uno de sus seminarios:

Vivimos, se nos dice a menudo, en un mundo de simulacros, vivimos en un mundo de clichés. Sin dudas. ¿Hay que acusar a los progresos, a ciertos progresos técnicos en el campo de las imágenes: la imagen-foto, la imagen-cine, 
la imagen-televisión, etc.? Bueno, pero ese mundo de las imágenes no existe solamente sobre las pantallas. Existe en nuestras cabezas, existe en las obras, existe en una obra (55).

Si hay un escenario en el cual las imágenes hicieron del cliché el escenario por excelencia fue la fotografía de la tarjeta postal. Gracias a la repetición constante de lugares emblemáticos y formatos de veduta, de la replicación de gestos y estandarización de los lugares, a fuerza de hacer una presencia cada vez más enmascarada del lugar, es que se terminó por desenmascararlo. Por ello es que el cliché de la imagen de 1900 puede asociarse directamente a la estética del kitsch de tiempos posteriores (Franco 6). Pueden verse dos consecuencias en esa tensión: la primera, es la referencia directa a un romanticismo puesto en evidencia, que a fuerza de intentar ejecuciones románticas pasó a ser "romantizante", empalagante, un pastiche. Un ejemplo eran las escenas de las calles, en las cuales el registro deja de narrar una anécdota singular o de construir personajes alrededor de las escenas narradas (como sucedía con los cuadros de costumbres de la Comisión Corográfica), y en cambio desnuda la perspectiva y produce de calles y edificios un panorama casi etnográfico, como efectivamente llegaron a ser algunas de las postales. En otro caso, aunque reprodujera las temáticas que en

FIGURA 13

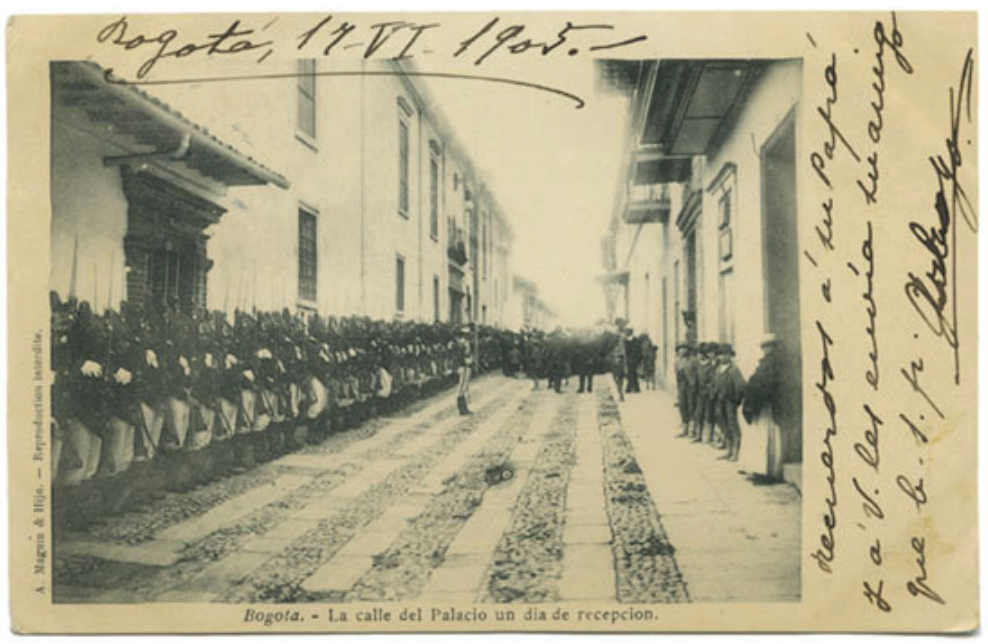

Mercado popular, Colombia. Anónimo. Cartulina Postal a blanco y negro. Sala de Libros Raros y Manuscritos, Biblioteca Luis Ángel Arango, Bogotá, 1907. 
pintura u otro género tenían una relación romántica, la frialdad documental de la cámara fotográfica, aunque la imagen se pintara o se adornara con esquelas o marcos sombreados, solo hacía de la fotografía un registro mucho más cliché. Dos escenas retratan esa frialdad. Por un lado, un mercado popular, aunque no podemos distinguir el lugar es probable que se trate de la Plaza de San Victorino en Bogotá [Figura 13]. Se puede distinguir la dinámica agitada del comercio: por un lado, las vasijas de barro en los costados; por otro, los vendedores que se encuentran en las partes traseras de las ventas, y por último un sendero no bien definido donde pasan los compradores. Solo viendo con atención se puede distinguir entre las dos formas de vestir: ruanas, alpargatas y sombreros por parte de los vendedores, y algunas mujeres vistiendo chales, faldas largas y con el cabello trenzado.

El otro ejemplo es la imagen del Carnaval de Barranquilla [Figura 14].

No es solo por la falta de gente sonriendo - la sonrisa en fotografía aparecería solo hacia mediados de los años 20 (Fabry) - que la fotografía resulta más un documento frío que la transmisión de un recuerdo de días festivos en el trópico. El carácter forzado y rígido de la pose incluso de los niños que están a los costados, o del hombre que se encuentra en el centro no pueden evitar que a pesar de la intención de "decorar" la foto parezca más un ritual que una celebración. Eso que en la imagen pintada podía

FIGURA 14

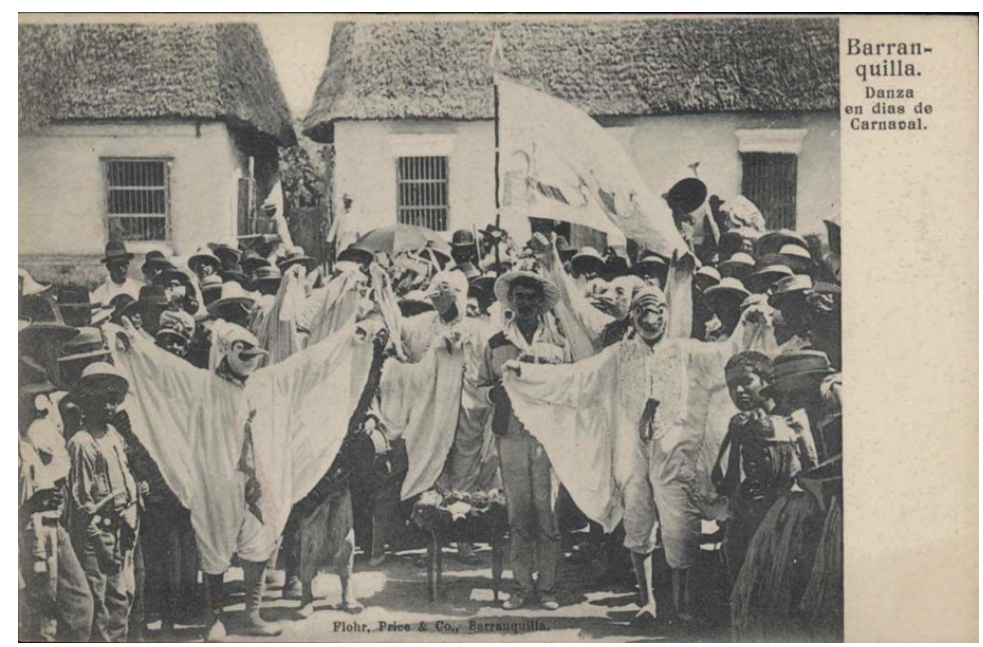

Barranquilla, Danza en días de Carnaval. Flohr, Price \& Co.

Cartulina Postal a blanco y negro. Sala de Libros Raros y

Manuscritos, Biblioteca Luis Ângel Arango, Bogotá, 1904. 
parecer romántico, alegórico o simbólico, en la fotografía de la postal luce crudo y directo, como si de repente la ensoñación que producía la imagen pintada resultara desnuda. La ilusión de fiesta se traduce en gestos y cuerpos hieráticos, como inertes. Sin artilugios románticos, la escena pierde la capacidad de ensoñación que podría evocar la fotografía de los referentes visuales que comenzaban a viajar por el mundo a través de las postales. Por eso su imagen recuerda más al registro etnográfico que a la ilusión de una temporada de fiesta.

No es solo en la imagen en sí o en su reproducción donde la misma escena adquiriría una transformación, sino también en los otros lugares donde se posaba el cliché de la postal: en la colección, el desplazamiento o el mensaje escrito. Las postales construyen una serie de referencias simbólicas sobre uno y otro lugar y el lenguaje planteado, aunque siempre subjetivo y dependiente de cada remitente, partía casi siempre de la misma encrucijada: el mensaje impersonal de una carta que se ofrece siempre abierta. Esos clichés, lugares comunes que comprometen el lugar creativo del artista, eran igualmente el lugar de producción de la tarjeta postal. No es gratuito que Jacques Derrida encontrara en estas el motivo para la reflexión de un mensaje que, a fuerza de reproducir lugares comunes, pasara a convertirse en ningún lugar: "una tarjeta postal no es sino un pedazo de carta que en el momento mismo de ser recogida se hace pedazos, y cada pedazo parece simple, ingénuo y sobretodo indivisible, inanalizable" (52). Hay una multiplicidad de mensajes que pueden referirse en la tarjeta postal: desde íntimas referencias familiares a comunes saludos cordiales (clichés una vez más). Incluso la tarjeta que no fue utilizada es también un diciente comentario a un mercado que no dependía del viaje para su subsistencia, pues coleccionar postales resultó como una consecuencia (o una patología) a la dinámica misma de esta imagen popular.

La difusión de la imagen está definida por su repetición. Uno de aquellos aspectos que lo demuestra fue cuando esas imágenes fotográficas, desprovistas de artificios de grandiosidad o fantasía, buscaron retornar a las formas estéticas de la pintura. Podemos verlo en varios referentes al paisaje de Cartagena.

A pesar de ser en el siglo xx un gobierno centralista, las regiones de Colombia gozaron siempre de autonomía tanto política como de identidad local, lo que se reflejó igualmente en la autonomía cultural de las ciudades. En Cartagena, al fotógrafo Juan Trucco, así como a los hermanos Jaspe, se les debe un gran número de las primeras imágenes de la ciudad. Para buena parte de los proyectos postales que se dieron a comienzos del siglo $\mathrm{xx}$ fueron tomadas directamente sus fotografías como modelos. La imagen del Pie del Cerro, realizada en 1890, registró la ciénaga, la vivienda y los caceríos apenas asentados. Para mediados del siglo xx, el editor J. V. Mogollón tomó parte de estas imágenes para el desarrollo de una serie postal. Sin embargo, carente de la magia romántica de una vista pintada, la interpretación fotográfica debía adquirir elementos para que tuvieran una mayor presencia simbólica [Figuras 15 y 16]. 
FIGURA 15

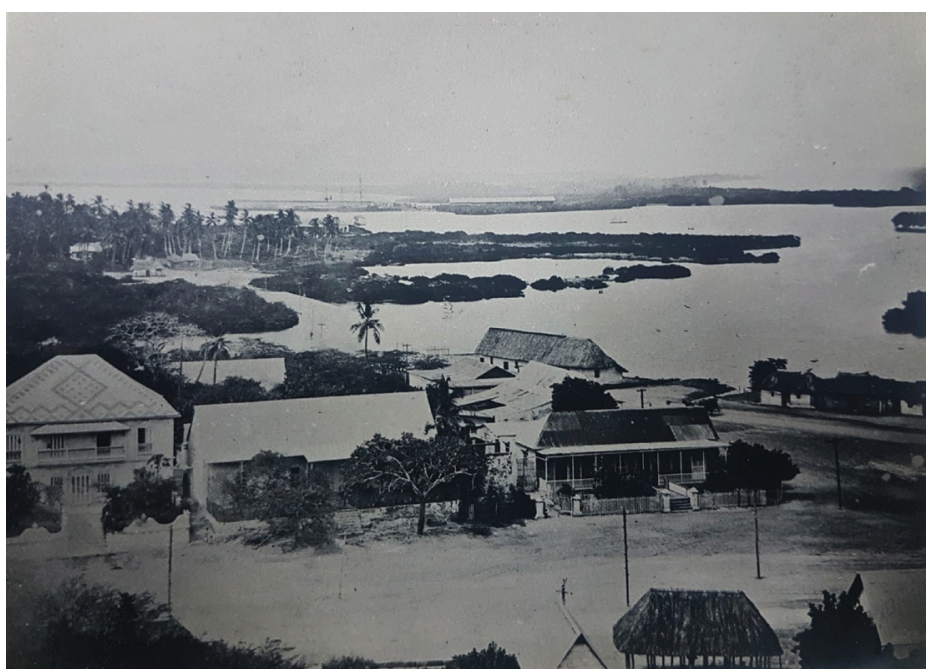

Panorámica de la isla de Manga, Cartagena. Juan Trucco.

Fotografía a blanco y negro. Biblioteca de la Universidad Tecnológica de Bolívar, Cartagena, 1890.

\section{FIGURA 16}

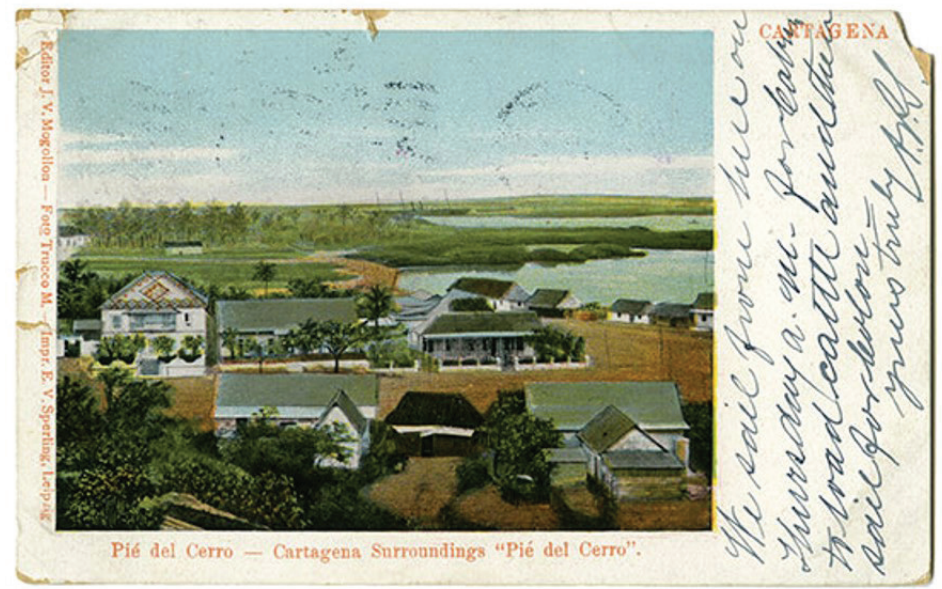

Pie del Cerro - Cartagena. J. V. Mogollón. Tarjeta postal, fotografía a blanco y negro coloreada. Sala de Libros Raros y Manuscritos, Biblioteca Luis Ángel Arango, Bogotá, Ca.1908 
La imagen desarrolló toda una recomposición de la imagen original. La tonalidad fue variando de acuerdo a la distancia planteada. El cielo, como era de esperarse, aparece con un tono azulado y gradual, a la vez que se esbozaron sutiles nubes en los costados. El lago adquirió una tonalidad verdosa. Las plantas adquieren detalladas formas de acuerdo a diferentes follajes, con diversas tonalidades. Aunque el recurso más evidente fue el color, no fue el único. El reflejo de las dunas aparece en las orillas del lago, pero lo más importante, la perspectiva, y con ello el punto de fuga determinante en la fotografía de 1900, desaparece para ajustar de un modo equilibrado de nuevo el horizonte, como sucedía con las vistas pintadas. El nombre cambia y se dispone en versión bilingüe, como hemos visto que sucede con frecuencia en las adaptaciones de las postales. Como un detalle particular podemos ver que es de las pocas postales donde además podemos ver el nombre del fotógrafo.

Esa presencia embadurnada y colorida del lugar, que hoy podemos interpretar casi como kitsch, fue uno de esos intentos de la imagen fotográfica por devenir pictórica en el medio de la postal. No es gratuito que, por ejemplo, los surrealistas hayan sido grandes coleccionistas de este medio (Chéroux y Eskilden 201). Otra imagen nos permite ver esas referencias. En este caso se trata de un paisaje natural. La fotografía, más allá de su elevado deterioro, nos permite reconstruir los elementos básicos de la vegetación de manglar en un primer plano y al fondo el emblemático cerro de la Popa, ya visto en las imágenes de la comisión [Figura 17 y 18 ].

La adaptación a tarjeta postal no solo transformó lo que al parecer eran secos matorrales en vegetación nativa, sino que además despejó el sendero y transformó el fondo de un escenario denso y sin forma alguna en toda una población a las laderas del cerro. El volumen del cerro adquirió profundidad y produjo lo que al parecer serían senderos para llegar a la cima. Pero lo más importante, aquello que era solo la punta de la montaña, adquirió en la postal el carácter de una imponente construcción que se erige cual castillo en la cima de un pueblo medieval.

La pintura pretendía y copiaba de la pintura la fidelidad con relación al volumen, proporción y dimensión de la fotografía, y utilizaba el medio para ganar en precisión y perfección de la copia. Pero en este caso la fotografía, a través de su embarnizado tratamiento para transformarse en un símbolo postal, jugaba con recursos pictóricos para transformar el documento técnico de una impresión fotográfica en un emblema simbólico que jugara con el elemento básico de la fotografía en la postal: la enunciación de un lugar. La reivindicación de la pintura en aras de producir una dimensión emblemática a la fotografía creaba involuntariamente un efecto distinto, producía un emblema irreal, casi ilusorio, que se desprendía de su carácter documental. La reproducción de estas imágenes, su uso cotidiano, su manipulación, y sobre todo su dislocación, producen en ellas un nuevo efecto, la construcción de un símbolo. Poco a poco, la realidad que interpreta la fotografía puede llegar a ser o no relevante. Lo importante era que como referencia adquiriera un símbolo que lo identificara: una calle, un templo, una plaza, una montaña. Una 


\section{FIGURA 17}

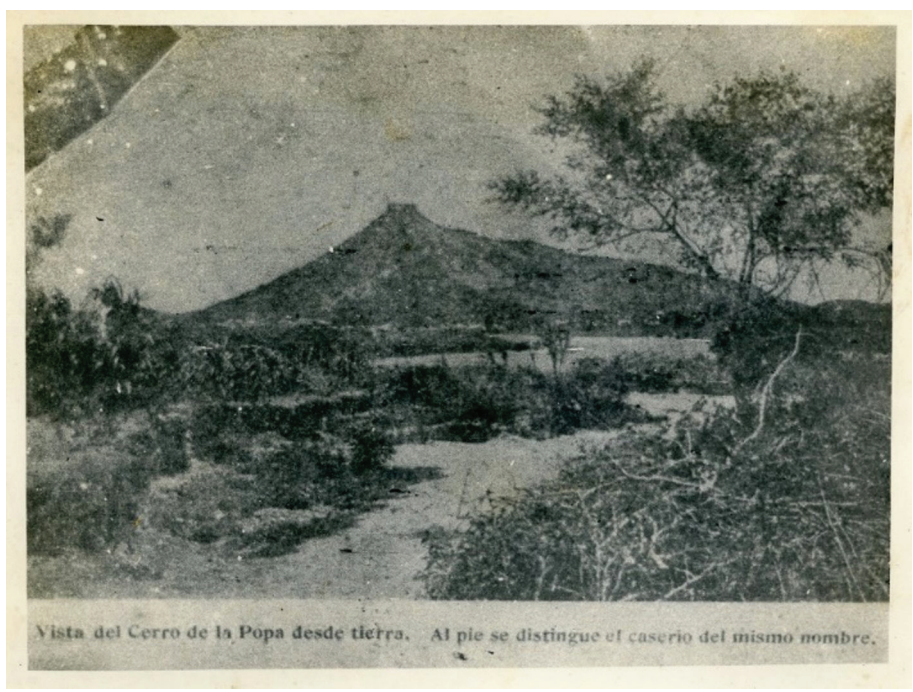

Vista del cerro de la Popa. Sin identificar. Fotografía blanco y negro. Biblioteca de la Universidad

Tecnológica de Bolívar, Cartagena, 1900.

\section{FIGURA 18}

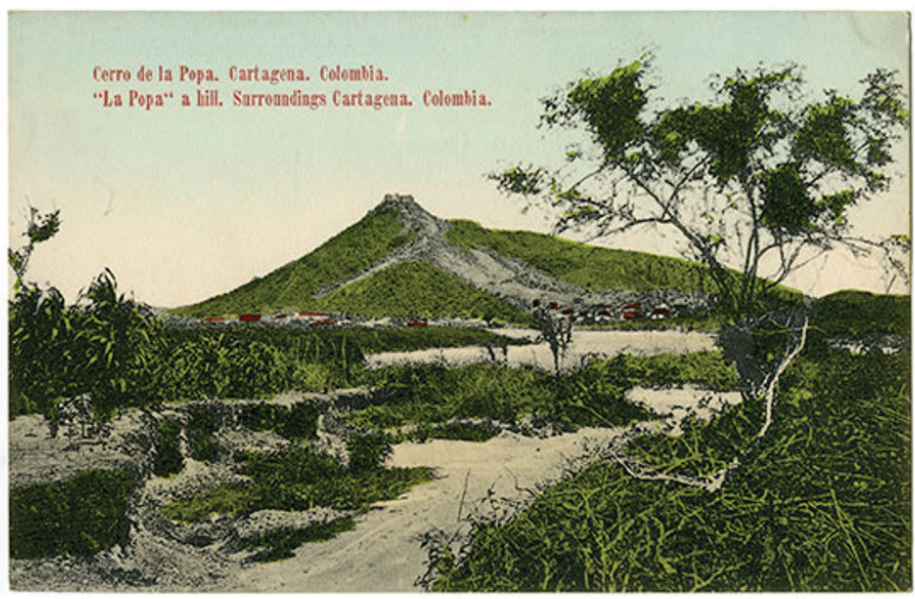

Cerro de la Popa, Cartagena. Sin identificar. Tarjeta postal, fotografía a blanco y negro coloreada. Sala de Libros Raros y Manuscritos, Biblioteca Luis Ángel Arango, Bogotá, Ca. 1905. 
vez que ese símbolo fue establecido, debía repetirse constantemente hasta que uno y otro, símbolo y lugar, fueran una sola cosa e incluso que el símbolo sustituyera el lugar mismo. Ese nuevo símbolo es el que cierra y concluye la unidad que produce el choque con las formas de entender un espacio. Ese símbolo, hijo de la fotografía pero autónomo en sus características, se transforma en un synecdoche, un extracto que refiere al todo. Un emblema que lejos de evocar a la memoria produce un nuevo lugar, un recuerdo quizás de lo no vivido o lo no existente, pues como analizó Žižek: "la repetición es 'memoria invertida', un movimiento hacia la producción de lo Nuevo y no la reproducción de lo Antiguo" (29).

\section{Conclusiones}

En el siglo XIX, las representaciones del paisaje colombiano se articulaban a ideas y representaciones que buscaban preservan un estado costumbrista y un escenario poético de la naturaleza que, a pesar de ser recurrente, se movía en un escenario limitado de producción. Proyectos como la Comisión Corográfica, el Papel Periódico Ilustrado y los artistas paisajistas de la Escuela de la Sabana buscaron reconocer, así como hacer público, el espacio colombiano a través de la producción de imágenes pintadas o grabadas. Con la técnica fotográfica, que comenzó a establecerse en Colombia, la forma de crear una imagen del paisaje impactaría en la forma misma de identificar los lugares. Los primeros intentos fotográficos de paisajes y vistas fotográficas en Colombia procuraban continuar con la línea propuesta por la estética visual fotográfica del Grand Tour, que había impactado y definido en cierto modo la manera de interpretar con la cámara los lugares emblemáticos. Sin embargo, el choque entre el paisaje colombiano, la tradición pictórica y la relación propia del fotógrafo con el espacio produjo una serie de tensiones estéticas que se desarrollaron en la imagen, particularmente con la difusión del paisaje a través de la fotografía de la tarjeta postal. Con ella, se estableció una relación pública con la imagen que, lejos de la pretensión nacionalista o el proyecto social que implicaba la producción visual previa, reinterpretó de nuevo lugares y escenarios del país y contribuyó a hacerlos públicos. En otras ocasiones, divulgó por vez primera imágenes de un lugar. Con la tarjeta postal, las prácticas de representación, asociadas a prácticas de consumo y colección, impactaron no solo en la forma en que se representaban los lugares, sino además en la creación y divulgación de sus propios símbolos. Al representar los lugares en la dinámica de la copia fotográfica, la fotografía definió y transformó los lugares mismos, reconociendo su propia naturaleza y dando forma a aquello que le sería emblemático.

La fotografía en Colombia está pendiente de ser estudiada con detalle y rigurosidad, analizando tanto sus aspectos temáticos como los diversos formatos en los que fue reproducida. A partir de este estudio se han comenzado a rescatar nombres de fotógrafos, así como imágenes desconocidas en colecciones que una vez inventariadas 
han permitido entender la forma en la que Colombia definía su propia interpretación del Grand Tour. Así como el paisaje, la representación del hombre tuvo una especificidad que merece ser estudiada a fondo en investigaciones que profundicen en la imagen fotográfica. Además, la tarjeta postal en Colombia es una fuente de la que se sabe muy poco, a pesar de que los grandes fotógrafos del país contribuyeron a desarrollar esta industria. Como se presentó en este texto, detrás hay toda una interacción entre paisaje, representación e identidad que sería interesante continuar explorando en otras épocas.

Quizás lo más sugestivo que ofrece el desarrollo de la postal fotográfica alrededor de 1900 es que a fuerza de repetición la operación de cliché logró que el emblema pasara de posarse en la copia de la imagen, a ser el lugar mismo. De la copia de un lugar, a transformar el lugar en el emblema de la copia. Es por ello que quizás en las postales de los primeros años del siglo xx se encuentre la primera arqueología del viaje contemporáneo.

\section{Agradecimientos}

Agradezco principalmente a la gerencia de investigaciones de la Universidad EAN, quienes son los principales soportes de este proyecto. A las estudiantes Judy Aidé Castillo, Lucía Rodríguez y Carolina Rodríguez, que colaboraron como asistentes del proyecto. Finalmente agradezco al Kunsthistorisches Institut en Florencia, Italia, y especialmente a su director, el profesor Gerhard Wolf, por permitirme realizar una estancia de investigación en la cual pude culminar la escritura del presente texto.

\section{Referencias}

Amossy, Ruth. "D’une Culture à l’autre: Réflexions Sur La Transposition Des Clichés et Des Stéréotypes". Palimpsestes, n. ${ }^{\circ}$ 13, 2001, pp. 9-27.

-_. "La Notion de Stéréotype Dans La Réflexion Contemporaine". Littérature, n. ${ }^{\circ} 73$, 1989, pp. 29-46.

Amossy, Ruth y Anne Herschberg Pierrot. Stéréotypes et Clichés. París, Armand Colin, 2015.

Amossy, Ruth y Terese Lyons. "The Cliche in the Reading Process". Substance, n. ${ }^{\circ}$, 1982, pp. 34-45.

Appelbaum, Nancy. "Envisioning the Nation: The Mid-Century Colombian Chorographic Commission". State and Nation Making in Latin America. Nueva York, Cambridge University Press, 2013, pp. 375-98.

Ávila, Roberto. Imagen fotográfica, las primeras décadas de fotografía en Tunja. Tunja, Universidad Pedagógica y Tecnológica de Tunja, 2004. 
Calderón Schrader, Camilo. Salón Nacional de Artistas, 50 años de historia. Bogotá, Colcultura, 1990.

Candelier, Henri. Rio-Hacha et Les Indiens Goajires. París, Firmin-Didot, 1893.

Chéroux, Clément y Ute Eskilden. La Photographie Timbrée: L'inventive Visual de La Carte Postale Photographique. Göttingen, Steidl/Jeu du Paume, 2007.

D'Agostini, Corrado. Photographic Lenses of the 1800's in France. Londres, Bandecci \& Vivaldi, 2011.

Daston, Lorraine J. y Peter Galison. Objectivity. Cambridge y Londres, MIT Press, 2010.

Deleuze, Gilles. Pintura: El concepto de diagrama. Buenos Aires, Cactus, 2007.

Derrida, Jacques. La tarjeta postal, de Sócrates a Freud y más allá. México, Siglo Xxi, 2001.

Driver, Felix, editor. 'OOn the Spot': Traveling Artists and the Iconographic Inventory of the World, 1769-1859”. Tropical Visions in an Age of Empire. Chicago, University of Chicago Press, 2005, pp. 25-42.

Fabry, Merrill. "Now You Know: Why Do People Always Look So Serious in Old Photos?" Time Magazine, 2016. Disponible en http://time.com/4568032/ smile-serious-old-photos/

Fajardo, Marta. "Manuel Dositeo Carvajal y el nacimiento del paisaje en Colombia". Ensayos: Historia y Teoría Del Arte, n. ${ }^{\circ}$ 6, 2000, pp. 95-115.

Franco, Marie y Miguel Olmos. "Lieux Communs: Histoire et Problématiques”. Pandora: Revue d'etudes Hispaniques, n. ${ }^{\circ}$ 1, 2001, pp. 11-28.

Frange, Pierre Henry y Patricia Limido. Les Inventions Photographiques Du Paysage. Rennes, Presses Univérsitaires de Rennes, 2016.

García Castro, Álvaro. Auguste Morisot, un pintor en el Orinoco, 1886-1887. Caracas, Planeta, 2002.

König, Brigitte. "El Café Literario en Colombia: Símbolo de la vanguardia en el siglo xx”. Procesos Históricos, vol. 1, n. ${ }^{\circ}$ 2, 2002.

Jiménez Hernández, Wilson. “El Papel Periódico Ilustrado y la configuración del proyecto de la regeneración (1881-1888)”. Historia Crítica, n. ${ }^{\circ}$ 47, 2012, pp. 115-38.

Latour, Bruno. "Drawing Things Together". Representation in Scientific Practice. Ed. Michael Lynch. Cambridge, MIT Press, 1990.

López Hurtado, Mariana. La tarjeta postal como documento. Estudio de usuarios y propuesta de un modelo analítico. Aplicación a la colección de postales del Ateneo de Madrid. Madrid, Universidad Complutense de Madrid, 2013.

Lorenz, Dieter. Fotografie Und Raum. Beiträge Zur Geschichte Der Stereoskopie. Berlín, Waxmann, 2012.

Pérez Benavides, Amada Carolina. Nosotros y los otros: Las representaciones de la nación y sus habitantes, Colombia, 1880-1910. Pontificia Universidad Javeriana, 2015.

Röthlisberger, Ernst. El Dorado. Reise Und Kulturbilder Aus Dem Südamerikanischen Kolumbien. Bern, Schmid und Francke, 1898.

Rouillé, André. La Photographie En France, Textes et Controverses, Une Anthologie. París, Macula, 1989. 
Sanz de Santamaría, Pablo. El viaje de Frederic Edwin Church por Colombia y Ecuador. Abril-octubre de 1853. Bogotá, Universidad de los Andes, Thomas Greg \& Sons, Villegas editores, 2009.

Sauer, Carl O. "La Morfología Del Paisaje." Nuevos Mundos, vol. 15, 2006. Disponible en: http://polis.revues.org/5015

Schwartz, Hillel. The Culture of the Copy: Striking Likeness, Unreasonable Facsimiles. Nueva York, Zone books, 2013.

Serrano, Eduardo. Historia de la fotografía en Colombia. Bogotá, Villegas Editores, 1984.

Simmel, Georg. El individuo y la libertad: Ensayos de críticas de la cultura. Barcelona, Península, 1986.

-- Sociología, estudios sobre las formas de socialización. México, Fondo de Cultura Económica, 2014.

Tuan, Yi-Fu. Space and Place, the Perspective of Experience. Mineápolis, University of Minneapolis, 1977.

Uribe, Verónica. "Translating Landscape: The Colombian Chorographic Commission". Journal of Arts and Humanities, vol. 3, n. ${ }^{\circ}$ 1, 2014, pp. 126-36.

Varios autores. Andrés de Santamaria 1860-1945. Bogotá, Villegas Editores, 1986.

Warner Marien, Mary. Photography, a Cultural History. Londres, Lawrence King, 2002.

Wegelin, Lucía. "El fundamento estético de la perspectiva relacional: Georg Simmel como pensador crítico". Digithum, n. ${ }^{\circ}$ 19, 2017, pp. 1-10.

Wilde, Oscar. Selected Prose. Fairfield, $1^{\text {st }}$ World Library, 2004.

Zevi, Filippo. Gli Alinari Fotografi a Firenze. Florencia, Edizioni Alinari, 1977.

Žižek, Slavoj. Órganos sin cuerpos. Valencia, Pre-Textos, 2004.

Enviado: 31 de enero de 2019 Aceptado: 17 de septiembre de 2019 